This is a pre-copyedited, author-produced version of an article accepted for publication in The British Journal of Social Work following peer review. The version of record Hood, Rick, Brent, Maria, Abbott, Simon and Sartori, Daniele (2019) A study of practitioner-service user relationships in social work. The British Journal of Social Work, 49(3), pp. 787-805. is available online at: https://academic.oup.com/bjsw/article/49/3/787/5098781/. 


\title{
A study of practitioner-service user relationships in social work
}

\begin{abstract}
This paper reports on findings from a qualitative study of practitioner-service user relationships in social work. The research aimed to identify social workers' personal constructs of their relationships with service users and explore how these constructs differed across roles and settings. A qualitative methodology employing a variation on role repertory grid techniques was used to carry out semi-structured interviews with social workers. Twenty five social workers from seven different practice settings were interviewed and altogether identified over two hundred personal constructs. The research team undertook a thematic analysis of these constructs along with their explanation and discussion in interview transcripts. The results identified twenty-five superordinate constructs within ten core themes, which reflected practitioners' experience of relationships, their systemic context, along with dynamics of power and collaboration. The constructs were often found to contrast a positive or preferred attribute of relationships with a more negative or challenging attribute, although the reality of relationships was often found to be complex and ambiguous. Some implications are explored for the current theoretical context of relationship-based practice in social work.
\end{abstract}

\section{Keywords}

Relationship-based practice, critical practice, personal constructs, practitioners, service users, social work theory 


\section{Introduction}

Contemporary social work demonstrates a rather ambivalent attitude to relationships. Social services cannot be provided without some sort of relationship between provider and user, yet the institutional context of social work often seems inimical to the kind of relationship that service users want (Howe, 1998; Trevithick, 2003; Ruch et al., 2010; Murphy et al., 2013). The profession itself has also become sceptical of its psychodynamic tradition, which was criticised by behaviourist and 'radical' perspectives even before it was supplanted by case management, legal processes, IT-based workflow systems and assessment protocols. Advocates of relationship-based practice have therefore steered clear of nostalgia for a lost golden age, arguing instead for pragmatism in the face of complex problems, in which 'a successful outcome may not be possible unless time is taken - and skills used - to establish some form of meaningful and constructive connection with the individuals in question' (Trevithick 2003: 168). As Howe (1998) puts it, the relationship is where 'most of the important things happen, for good or for ill, whether social workers recognise it or not' (1998: 45).

There are various theoretical approaches to relationships between social workers and service users. Humanist core values, such as authenticity, empathy and respect are often seen as underpinning practice, particularly in the 'person-centred' tradition (Neukrug et al., 2013). Psychodynamic theory still seems the preferred approach in much of the literature (e.g. Ruch et al., 2010), underpinned by the distinction between conscious and unconscious drivers of human interactions and behaviour (Brandell, 2013). Strong emotions such as anger, distress, and anxiety are seen as shaping our responses to stressful or overwhelming situation, giving rise to dynamics such as transference and counter-transference, splitting and projection, which play out in our relationships with others. These concepts are then used by practitioners and their managers to disentangle the complexities and challenges of relationship-based work.

Other perspectives on relationships are provided by systems theory and critical theory. Systems approaches see relationships in terms of the interconnection of agents or elements in a system. In a closed system, these interconnections serve to maintain equilibrium or a 
'steady state, while in an open system they can also drive dynamic patterns of change that enable adaptation to the environment. Interactions between practitioners and service users are therefore seen as part of a wider network of relationships e.g. within and between families, communities, agencies and societies. Since the behaviour of complex systems is unpredictable, stable-seeming relationships may suddenly become volatile as the system undergoes a period of disruption and transformation (Nybell, 2001). Critical approaches, on the other hand, are interested in how dynamics of power, with their roots in social structures of discrimination, oppression and exclusion, become enacted and reproduced in everyday interactions and relationships (Fook and Askeland, 2006). Relationships between social workers and service users may serve to perpetuate or challenge power structures, so that dynamics of collaboration and conflict in a professional context will always have a broader socio-political dimension. Given the institutional context of social work, professionals are often seen as wielding power 'over' their clients, while at the same time the interplay of social differences, e.g. in terms of class, ethnicity or social capital, is likely to be experienced in a more nuanced, ambiguous way. In this sense, all three theoretical perspectives share a concern with the complex dynamics of relationships in social work but focus on different elements that are complementary but also contradictory in some respects. The contribution of this study is to explore how social workers actually conceptualise their relationships, with a view to informing the burgeoning literature on relationship-based practice.

\section{Methodology}

\section{Design}

The aim of the research was to explore how social workers from a range of practice settings conceptualised their relationships with service users. The research team consisted of three social work academics, whose respective backgrounds were in child protection, adult social care and mental health, as well as a specialist researcher with a background in social care and education. A literature review was first carried out in order to identify the most relevant theoretical frameworks for practitioner-service user relationships. The study's aims suggested a methodology based on hermeneutic psychology, given that it was primarily 
concerned with understanding the meaning of relationships to practitioners rather than with explaining relationships in terms of causal laws. For this study, a qualitative methodology based on role repertory technique (Fransella et al., 2004), an empirical application of personal construct theory, was used in order to explore how social workers conceptualised their relationships with service users. The method assumes that people tend to think in contrasts rather than in absolutes; for example, the idea of a 'short-term' relationship implies a contrast with a relationship that is long-term. Role repertory technique therefore aims to elicit a series of dichotomous constructs, which underlie how someone thinks about a topic. This was considered advantageous for capturing the dynamic and mutable nature of relationships in social work.

\section{Sample}

After the study was approved by the faculty research ethics committee, a purposive sample of 25 participants was recruited, comprising either three or four practitioners from seven service user groups as set out in Table 1 below. The purpose of the sample was to ensure a representative spread of social workers from different areas of practice. The majority of social workers agreeing to take part were employed in the statutory sector. All the social workers had been qualified for at least one year (i.e. more recent graduates had passed their assessed year in practice) and most had between 5 and 10 years' post-qualifying experience. Some of them had current or previous affiliations with the institution from which recruitment was being carried out, although their jobs were in a range of settings and local authorities, primarily in urban areas. All participants gave written informed consent to participate in the research.

Table 1: Sample of social workers and their practice areas

Insert Table 1 here.

Data collection 
Data collection was through semi-structured interviews with social workers using an adapted form of repertory grid technique (Fransella et al., 2004). The majority of interviews were carried out by two members of the research team. The sequence of questions was the same for each respondent. First they were asked to think of six service users with whom they had had a working relationship that they were prepared to discuss, and make a note of the respective pseudonym or initials on individual cards. They were then asked to choose at random three of these cards, each representing a different person. The interviewer would then pair up two of the cards and place them opposite the third one. The respondent was invited to think about their relationships with those three people and then consider how their relationship with the people on the paired cards was similar while also being different from their relationship with the third person. When they had identified this element of the relationship, they were then asked what would be its 'opposite' (e.g. long terms vs short term). The two answers were then written down as a dichotomous construct, i.e. a conceptual category with two opposite poles. The process was then repeated with another random selection of three cards, with at least one card different from a previous selection. The interview continued until all possible selections were used up, or until no new constructs emerged. Conventional use of repertory grid technique would have involved a final stage requiring the respondent to assign a 'rating' to all of their elements (here represented by the cards) for each construct in turn. However, since the purpose of the interview was only to obtain the constructs, this part of the tool was omitted. All interviews were recorded and transcribed verbatim by a third party, who anonymised the transcripts for the purpose of analysis.

\section{Analysis}

Transcripts were imported into qualitative data analysis software (NVivo 11). Initial coding linked each personal construct with the part of the transcript in which it had emerged. Since there were over two hundred of these constructs, each unique to the individual practitioner, a further stage of inductive analysis was carried out. To begin with, three members of the research team independently sorted all of the personal constructs into general thematic categories, referring to the discussion in transcripts to understand the meaning of constructs for participants. For example, the construct 'certainty about what client is trying 
to say VS never sure what the person wants' (Participant SW25) was considered to be part of a general theme around 'communication'. The research team then met to discuss their interpretation of categories and constructs and agree on a common framework of definition and inclusion. For example, 'communication' was distinguished from 'cooperation' by defining the former as being to do with the sending and receiving of messages in one-to-one interactions, and the latter to do with the dynamics of partnership working in particular cases. The next step in the analysis was to go back to the constructs within each general theme and include them within superordinate constructs that captured their meaning. For example, the construct cited above became part of the following superordinate construct: 'I often misunderstand what service users are trying to tell me VS I always understand what service users are trying to tell me.' Again, three members of the research team did this independently and then met to agree on definition and inclusion of constructs. Overall, the study found ten thematic categories covering twenty five superordinate constructs on the relationship between social workers and service users. The final stage of analysis was to use the 'matrix coding' query in NVivo to compare which themes and constructs had emerged in the discussion with social workers from different practice settings.

\section{Findings}

The analysis of interviews identified ten thematic categories and 26 superordinate constructs. The thematic categories were: closeness and intensity, feelings, trust and openness, communication, conflict, cooperation and engagement, networks, power and authority, creativity, and dependency. They outline the broad concerns and preoccupations underlying these social workers' perception of relationships. Within each of these categories, superordinate constructs indicate characteristic ways of thinking about similarities and differences between relationships, and so represent a dichotomy (oppositional contrast) but also a continuum on which any given relationship could be located. A complete list of constructs is attached as a supplement to the online version of this paper. Some constructs were focused on attributes of the relationship itself while others focused on attributes of practitioners or service users that were perceived to affect the relationship (see Figure 1). In many constructs, one element was considered more positive than the other, e.g. practitioners preferred relationships in which they could be 
creative and flexible to those in which they were constrained by organisational procedures In some constructs, there was ambiguity about which element was preferable, e.g. whether contact with service users was frequent or infrequent, or the extent to which professional boundaries were fixed or could sometimes be crossed. The basic organising principles of the constructs are illustrated below in Figure 1, and an expanded version summarising all of the elements is presented in Figure 2 later on in the paper.

Figure 1. Organising principles of the constructs

Insert Figure 1 here

In what follows, the significance that practitioners attached to their constructs will be illustrated with examples within each thematic category.

Closeness and intensity

There were four constructs linked to the theme of closeness and intensity (see Appendix Table). Frequency of contact was highlighted by social workers in various fields of practice. For one participant (SW5, learning disabilities), frequent contact was sometimes hard to manage, particularly if it meant being bombarded with phone calls every day; on the other hand, it offered the prospect of a regular update on people's welfare. It was therefore a feature of the relationship that could be fine-tuned as the social worker got to know the person in question. For a social worker in youth justice, on the other hand, frequency was usually mandated by court orders; the actual level of contact therefore reflected the young person's attitude towards compliance and engagement. Another interpretation was supplied by a mental health social worker, for whom frequent contact was associated with crisis situations rather than with more stable patterns of treatment and care.

One social worker (SW5) considered more frequent contact to be characteristic of shortterm work. However, the contrast between short-term and long-term relationships was a separate construct that was not necessarily linked to frequency. Some participants seemed 
to see long term work as having a preventative function. For example, one social worker reported that the family of an elderly man used to ring her informally for advice over a number of years, and that this compensated in some respects for the lack of a long term social worker'. Another participant, who worked with older people with physical disabilities, thought that a long term relationship with a service users helped to prevent the escalation of difficulties, avoid hospitalisation and promote community living; on the other hand, she suggested that 'if you don't know somebody and you get something as a crisis you might be more inclined to think that person does need a placement now' (SW4, older adults and physical disabilities).

The question of emotional investment in the relationship was construed by some social workers from their own perspective and by others from the perspective of service users. Among the latter were references to people who confided in their social workers and who 'know they can always come to me' (SW4). One youth offending worker compared someone who had dropped into the office to see her, 'even after he'd finished his Order and was an adult', with others who 'if they see you in the street they might try and cross the road!' (SW15, youth justice). For these interviewees, emotional involvement was largely attributed to service users. Others emphasised the significance of emotional connection on the part of professionals:

\begin{abstract}
'It's those families that you don't feel any connection with. I had one of those cases, and it was horrible, and I used to feel miserable, because I didn't have any willingness to work with the family' (SW14, children and families).
\end{abstract}

For this participant, a lack of connection was experienced as deeply uncomfortable and had the potential to undermine her work with the family; in contrast, with another family she worried that empathising too much with the parents might cause her to lose focus on the children. A different social worker noted that the emotional intensity of the work could lead to feelings of guilt 'when you can't deliver what you would like to deliver', or feeling that she had let people down 'when they were unhappy about something' (SW10, substance misuse). For these social workers, the emotional labour of building and maintaining 
relationships was an important part of the job and one that could be perceived both as a benefit and as a burden.

\section{Feelings}

Constructs associated with the theme of feelings tended to draw a comparison between negative and positive emotions. Social workers enjoyed contact with service users who had come to trust them, whose behaviour was relaxed, and who expressed satisfaction or a sense of humour. These relationships contrasted with people who presented as angry or mistrustful, whose behaviour was challenging, and whose stories (initially at least) came with a lot of sadness and pain. Some participants mentioned the frustration of working with people who did not seem to make progress and where interactions and conversations seemed constantly to circle back to the same issues:

You feel like you're banging your head against a brick wall sometimes and you're having the same conversations all the time. (SW16, adults with physical disabilities).

Social workers generally acknowledged that dealing with such emotions was part of their role; indeed, making any kind of progress in difficult cases also gave cause for satisfaction. While social workers expressed negative feelings about service users who acted negatively towards them, risking a vicious circle of adversarial or mutually dissatisfying encounters, they also recognised that 'small victories (SW14), could lead - however torturously - in the right direction.

\section{Trust and openness}

There were three superordinate constructs linked to the theme of trust and openness. One social worker, who worked with physically disabled adults (SW17) and considered the degree to which she - along with other practitioners - sought to be open and transparent with service users about their role in assessing eligibility and means to pay. Other participants explored the reasons for attitudinal differences on the part of service users. Some distinguished between people who were open about what was going in their lives 
with those who were more reluctant to disclose information. Some equated openness with honesty, so that the distinction between guardedness and dishonesty was somewhat lost, i.e. people described as 'honest and open' were compared to people whose statements were unreliable or who tried to tell the social worker what they wanted to hear. For example, one participant (SW6, older adults) referred to a family in which some people's claims to have lasting power of attorney over health and welfare for an elderly relative had been accepted at face value by many professionals but were eventually discovered to be untrue.

Another set of constructs contrasted service users who trusted and confided in their social workers with those who were distrustful and tried to avoid contact if they could. These constructs allowed more scope for considering the social worker's contribution to such dynamics. For example, one participant from a mental health background (SW13) thought that her work was more effective if she was able to establish 'a certain level of trust' but this would be hampered if she were seen to be 'going by the diagnosis', i.e. assuming that the existence of a mental disorder limited what was possible or achievable for the client. Several participants spoke of having to 'prove themselves' to service users, which might mean keeping promises, living up to a well-liked predecessor, or conveying an authentic commitment to the person: 'yes I'm here to do my job, but I'm here because I really care' (SW13, mental health).

\section{Communication}

There were two superordinate constructs linked to the theme of communication. The first contrasted 'clear and straightforward' contexts for communication with more complex and challenging ones. The latter was exemplified by service users who could not communicate verbally, for example because of disability, age or illness. In such cases, social workers found creative ways to communicate non-verbally and overcome perceived 'barriers', e.g. by using pictorial methods, becoming more attuned to people's body language and more comfortable with the physical or 'tactile' aspects of communication. One participant noted that challenges in communication put more onus on face-to-face interaction, as opposed to 
people who were 'able to contact me regularly and to call me each week and discuss whatever issues there are' (SW5, adults with learning disabilities).

A second set of constructs concerned the extent of mutual understanding between the social worker and the service user. For one participant, non-verbal communication was associated with more uncertainty about what the other person was trying to 'say'. Another made a more general point about how messages (i.e. the content of communication) could be interpreted differently by the receiver than was intended by the sender: 'sometimes you find you thought you had one conversation and the person at the other end of the conversation, has a completely different conversation' (SW16, adults with physical disabilities). This social worker felt that while such misunderstandings were part of "human nature' they also reflected differences in priorities; part of her role with service users was 'to help them work out what is important and what isn't important, what needs to be prioritised, what doesn't' (SW16).

\section{Conflict and difficulty}

There were four superordinate constructs linked to the theme of conflict and difficulty. The first concerned the degree to which the families of service users were perceived to be supportive of the work and made it either easy or difficult to work in partnership with them. Most of the participants who brought up this issue were working with adults with physical or learning disabilities, where difficulties arose if family members were unhappy with the local authority's decision around eligibility and resources or if they disagreed with the care plan. Another participant, this time in youth justice, spoke appreciatively about how the mother of one young person would accompany him to sessions and help explain issues to him 'the way that she knew he'd understand it' (SW15, youth justice); contrasted with her experience in some other cases, in which the parents were either disengaged or took the young person's side.

The second construct within this theme contrasted relationships that were stable and harmonious with more volatile and unpredictable ones. Volatility was particularly evident when service users were experiencing stark fluctuations in mood, for example because of 
substance misuse or mental illness, and were likened to 'a rollercoaster' by one social worker (SW3, substance misuse) because of the degree to which some people would shift in their behaviour and presentation. Another source of unpredictability lay in the interplay of intentions and motivations driving the relationship. One participant, who worked in adoption, suggested that relationships were more challenging when carers were ambivalent about needing support, e.g. because they saw themselves as strong and capable. Another participant pointed out that improvements in people's health and welfare could end up having a destabilising effect on their finances, e.g. if they no longer met the criteria for disability benefits, which in turn disrupted their relationship with professionals.

The third set of constructs concerned the extent to which relationships were perceived as conflictual or collaborative. Conflict-ridden relationships were experienced in various ways: the perception that service users had unrealistic expectations, were searching for a pretext to make a complaint, or were constantly pushing boundaries. In contrast, collaborative relationships were characterised by mutual trust, light-hearted interactions, and a willingness to explore issues openly. Aggressive and threatening behaviour was explored in the fourth set of constructs, which tended to contrast 'angry clients' with those who came across as more welcoming and appreciative. People's anger was often attributed to their circumstances, e.g. precarious housing, drug and alcohol problems, abuse, breakdown in family relationships. One participant suggested that some people restrained their 'underlying anger that they will perhaps not listen to' (SW19, substance misuse), so that the relationship with a social worker allowed them to acknowledge and 'offload' some of those thoughts and feelings. Another participant referred to a type of 'justified anger' on the part of service users, which was 'still quite difficult because obviously someone can be shouting at you for no reason' (SW11, mental health). Social workers sometimes experienced antagonism to be targeted at them individually, particularly when they suffered verbal abuse or threats of violence, and this type of behaviour was considered inappropriate.

\section{Cooperation and engagement}


The theme of cooperation and engagement was composed of three superordinate constructs. The first considered service users who were resistant as opposed to those who were cooperative. Resistance was characterised in various ways: avoiding contact, not accepting help, being defensive or confrontational, responding to questions with monosyllabic answers, or expressing a preference for a female worker. In contrast, cooperation was characterised by a willingness to accept help, come in for appointments, comply with agreements and even act in a 'protective' manner on some occasions. The question of acknowledging concerns and challenging/being challenged underpinned the other two constructs under this theme. Only one participant considered the perspective of social workers, who might be inhibited from challenging service users when 'you know you will be shouted at and abused' (SW14, children and families). Other participants assumed that social workers were able to raise concerns but explored differences in how service users responded. People who were open to discussing problems were felt to be committed to changing their lives, which in turn made them more receptive to advice. Others were described as being 'in denial', disinclined to change, or as lacking capacity in their current circumstances to make informed decisions.

\section{Networks}

There were two sets of constructs within the overall theme of networks. The first concerned the extent to which relationships with service users were mediated by other people, such as parents, carers, interpreters. Unmediated relationships were usually considered advantageous because of the ability to interact directly with the service user. Where this was not possible, social workers had to consider that people's interests and agendas might not always be aligned:

'Sometimes the family member wants something different to the actual individual so it's difficult to get that balance and include that individual (SW5, adults with learning disabilities)

The second set of constructs was concerned with the presence of other professionals in the network and how this affected the relationship with the service user. More complex or challenging cases often involved many different agencies, which created additional layers of 
communication and dialogue. For example, one participant (working with substance misuse) reported that people could be more wary of disclosing information if they thought this might be passed onto other agencies, particularly children's services. For another participant (working with older people), the quality of service provided to service users by the care agency was one of the most important factors in her relationships with them.

\section{Power and authority}

The theme of power and authority was composed of three superordinate constructs. The first contrasted relationships that were led by the service user with those led by the practitioner. The former was generally held to be preferable, since it was characterised by a willingness to listen to people, find a shared understanding, work in partnership and promote people's rights. The 'opposite' kind of relationship put emphasis on professional expertise and institutional priorities, so that service users had little say in decisions or in how their problems were being understood and represented. More nuanced constructs considered the circumstances in which social workers might need to be more assertive or authoritative in their dealings with people. For example, one participant talked about service users who 'give me the script' (SW17, adults with physical disabilities), i.e. they were perfectly able to advocate for themselves so that the social worker could simply cite them verbatim in her assessment reports. However, this was not always possible; for some people she had to 'glean the script and write it myself', which might also involve challenging unrealistic expectations or dealing with antagonistic behaviour.

The second set of constructs within this category concerned the boundaries between professionals and service users, and how clearly they were understood and communicated. Some participants referred to the risks of being perceived as a 'friend' by service users, which might indicate a lack of clarity or misleading messages about the social worker's role. For others, a certain degree of boundary-crossing was associated with 'authenticity' and personal commitment to the relationship, as opposed to positioning oneself as 'the expert' or lapsing into professional jargon. For example, one social worker referred to the possibility of acknowledging emotion in her interactions with service users. Another reflected on her experience of working with a 'very knowledgeable, intelligent woman' in relation to her 
son's needs: 'it's almost as if you're having, a peer-to-peer relationship, it was almost like you didn't feel as if that was a parent you were talking with' (SW9, children and families).

The third set of constructs under this theme contrasted the level of coercion in relationships. Coercive relationships were characterised in various ways: being perceived as powerful, using one's authority to define people's lives, focusing on 'the offence' rather than on need (in a youth justice context), forcing decisions on people, or being 'strict' with them. In contrast, non-coercive relationships were characterised as equal, fair, empowering (to service users), respectful, and oriented towards people's needs. Generally the latter was seen as preferable but not without some ambiguity. For example, one social worker from a youth justice background suggested that young people who had been convicted of an offence offered her 'something concrete to work with', a kind of behavioural leverage that was lacking in the more 'liquid' relationships that she had experienced in child protection and with children in care, in which 'you're forever trying to respond to the changes and where they're going and what's happening for them' (SW22, youth justice).

\section{Creativity}

The theme of creativity was composed of two superordinate constructs. The first concerned the degree to which social workers were able to be flexible and creative in how they engaged and built relationships with service users, as opposed to being constrained by organisational procedures. Creativity was associated with professional discretion, the ability sometimes to go beyond one's official remit, to take a holistic approach, focus on emotional issues, and to incorporate the personal into the professional. These types of relationship were contrasted with those characterised by formulaic practice, reductionist or 'tickbox' approaches to people's needs, fixed and rigid methods of engagement, and an attitude of 'doing things by the book'. Creativity and flexibility seemed to be highly valued by all the participants who identified these constructs.

The second set of constructs contrasted impersonal and bureaucratic interactions with more informal and relaxed interactions. Some participants felt that a difference was made by 
meeting people in their home environment rather than in a clinical or institutional setting, whereas for others it was about finding the right mode of engagement:

'I got through to him through his love of dogs. I used to go for long walks with him and it was trying to give him space to be able to express things and to discuss things, without the formality of a meeting in a consulting room' (SW24, mental health)

\section{Dependency}

The theme of dependency was represented by one set of constructs that compared service users who were dependent on social workers to do things for them with those who were very self-reliant. Most of the constructs identified difficulties with one or other of these positions. Dependency was associated with service users having unrealistic expectations, wanting social workers to 'wave a magic wand', losing confidence in their own abilities, becoming overly compliant, needing a higher level of support. On the other hand, selfreliance was associated with risk-taking, distrust of social workers, over-confidence, and not asking for support. In the discussion of these constructs, a surfeit of either dependence or self-reliance meant that qualities associated with the opposite pole was construed more positively. For example, one participant compared service users who actively sought advice to those who acted recklessly and impulsively; in contrast, others spoke of encouraging service users to 'stand on their own two feet' and take decisions independently.

\section{Summary of findings}

- Social workers conceptualised their relationships with service users through twenty six constructs within ten thematic categories.

- Thematic categories represented social workers' underlying preoccupations in their relationships with service users. These categories were: closeness and intensity, feelings, trust and openness, communication, conflict, cooperation and engagement, networks, power and authority, creativity, and dependency.

- Constructs represented characteristic ways of thinking about similarities and differences between relationships. Some constructs were focused on attributes of the relationship 
itself while others focused on attributes of practitioners and service users that were perceived to affect the relationship.

- In many constructs, one element was considered more positive than the other, e.g. practitioners preferred relationships in which they could be creative and flexible to those in which they were constrained by organisational procedures

- In some constructs, there was ambiguity about which element was preferable, e.g. whether contact with service users was frequent or infrequent, or the extent to which professional boundaries were clear or could be crossed.

Figure 2. Summary of findings

Insert Figure 2 here

\section{Discussion}

In this study, social workers conceptualised their relationships with service users through a series of dichotomous constructs, which allowed them to contrast different kinds of relationships but also to explore what was important about them. No single theoretical perspective seemed to predominate but instead the constructs aligned and overlapped with various approaches to professional relationships in social work. For example, humanist core values were evident in the discussion of mutual trust and respect, of being emotionally 'invested, or 'led by the service user'. Critical theories assumed importance in participants' exploration of power and authority, coercion and control, while psychodynamic ideas influenced the discussion of emotions and dynamics of conflict, cooperation, openness and concealment. Finally, a more systemic perspective could be discerned in the way relationships were contextualised as part of broader networks and shaped by organisational and institutional factors. The conceptual underpinning of these constructs could therefore be characterised as theoretical eclecticism.

The emphasis on dichotomies - the contrast of opposing elements - led many practitioners to generate constructs comparing a positive attribute of relationships (e.g. openness, trust) 
with its more negative counterpart (e.g. guardedness, suspicion). This basic organising principle emerged even though practitioners were asked only to compare different relationships; they were not asked to distinguish between 'good' and 'bad' relationships, for example, nor to evaluate their own practice, nor to judge the behaviour of service users. One way to interpret the findings might be to perceive the attributes listed in the overlapping circles on the left-hand side of Figure 2 as an 'ideal-type' relationship something for social workers to work towards even if the reality looks different. Such an ideal would closely resemble the kind of helping relationships advocated in the counselling literature (e.g. Egan, 2013) as well as in person-centred approaches to social work (Murphy et al., 2013). In contrast, elements on the right-hand side of Figure 2 constitute the antiideal type, an array of negative attributes that get in the way of a productive relationship. A similar idea is the analogy of 'deposits' and 'withdrawals' sometimes found in the education and early years literature (Webster-Stratton, 1999; Joseph and Strain, 2004), which notes that our behaviour towards another person may be either conducive or inimical to a positive relationship with them. From the professional perspective, 'withdrawals' are sometimes unavoidable but should be outweighed by deposits if we wish to promote the other's (and our own) emotional resilience and self-esteem.

However, there are problems with this interpretation. An emphasis on distinguishing between 'positive' and 'negative' attributes arguably underplays the complexity of relationships discussed by participants. For example, while stable and harmonious relationships were preferred to volatile, unpredictable ones, positive change was sometimes seen to entail the latter and elude the former. While emotional investment in the relationship was valued, the emotions practitioners experienced were as likely to be negative as positive. Ambiguous elements were very dependent on context. For example, a long term relationship might prevent recurrent admissions to hospital, but also promote dependency; contact might need to be frequent at a time of crisis but have to be scaled back when the situation stabilised. Professional boundaries were particularly ambiguous, since a convincing case was made - by different practitioners - for both clarity and blurredness. The importance of context is also highlighted when different constructs are placed alongside each other. For example, an informal and friendly mode of interaction might suggest that professional boundaries are being crossed, but when a service user is 
being hostile and aggressive those interactions might be more formal and boundaries more obvious. While coercion might generally be seen as undesirable by practitioners, it clearly plays a part in many social work decisions and interventions. Is a service user who avoids and resists contact with social workers able to 'lead' the relationship, or is the professional compelled to be more assertive?

Such ambiguities and contradictions often seem to characterise professional relationships. From a psychodynamic perspective, unconscious motivations can undermine and subvert our conscious intentions (Brandell, 2013). From a critical perspective, social 'ways of being' that are transmitted to us through culture, e.g. in the form of conventions, prejudices, or common-sense, may lead us unwittingly to interact with people in ways that perpetuate oppression and injustice (Fook and Askeland, 2006). Theories of complex systems show that self-organising local interactions produce global patterns of behaviour without the latter being planned or designed. Each theory provides its own explanation and potential resolution for such troubling dynamics, including observation, introspection, supervision, reflection, critical thinking, and so on. However, the constructs illustrate the entangled nature of values, interests and priorities that such a process involves.

Howe (2014) characterises social work through an engagement with dichotomous debates such as care vs control, certainty vs uncertainty, facts vs values, thought vs feeling. Although we may have a preference for one over the other, these debates rarely resolve into a straightforward contrast between positive and negative. Instead they operate more like paradoxes, reflecting an underlying tension between elements that seem contradictory or incompatible but inviting a response that embraces those tensions simultaneously (Smith and Lewis, 2011). Howe's approach is to maintain the creative tension between the extremes, sometimes seeking to resolve the paradox dialectically by coming up with a third concept that synthesises the first two. For example, the respective merits of considering social work as both an art and a science are incorporated into the idea of social work as a 'craft'. In a this sense, practitioners' constructs could be seen as setting up a paradox rather 
than a guide to best practice; rather than seeking to conform to an ideal type, each relationship requires its own particular dialectic.

The dichotomies with which social workers wrestled in their relationships recall Bourdieu's famous description of social workers as agents of the state who are 'shot through with the contradictions of the state' (Bourdieu, 1999: 184). The questionable applicability of idealtype frameworks to such conditions remains a key challenge for social work, which has often laboured under efforts to prescribe and control frontline practice. In this respect, relationships could be seen as a reflection (or indeed as a bastion) of discretion and what Lipsky (1980) called 'street-level bureaucracy'. In social workers' accounts, we find conditions of practice characterised as much by ambiguity and creativity as by procedural constraints and adherence to rules. Dialogue, negotiation and trust co-exist with coercion, aggression and suspicion, requiring practitioners to constantly shift and adjust their stance. As Evans and Harris (2004) point out, this is entirely consistent with Lipsky's view of discretion in human services, a corollary of working with people who are 'unpredictable, varied and have different and dynamic needs' (2004: 878) and of needing to interpret vague and contradictory policy goals in the context of messy real-world situations. Such an analysis would suggest not only that the implementation of new policies, regulations, and models of practice should take into account relationship-based work, but also that relationships themselves will prove resistant to codification if not regulation.

\section{Limitations}

The study's intensive, qualitative design meant that social workers' conceptualisation of relationships could be grounded in their practice experience rather than being abstracted from it. This was crucial in order to understand the constructs' underlying ambiguity and complexity. However, the sample of participants was purposive and unrepresentative of social workers as a whole. It is therefore possible that interviewing more practitioners across a broader range of locations and settings would lead to yet more constructs and thematic categories. The design also limited the exploration of interconnections between constructs, e.g. whether relationships that were rated highly on one element, such as coerciveness, would also rate highly on another, e.g. conflictual. Answering this type of 
question would require a survey design and a much larger sample, and this seems an obvious follow-up to the findings presented here. Finally, the study does not consider the perspective of service users, which is a significant limitation given that they might be expected to conceptualise and evaluate the same relationships in a very different way from practitioners.

\section{Conclusion}

In conclusion, this study used a qualitative hermeneutic approach to explore practitionerservice user relationships from the perspective of social workers. The main result was a set of dichotomous constructs that addressed underlying differences and similarities between relationships. While many of the constructs seemed to contrast a positive or preferred attribute of relationships with a more negative or challenging attribute, there was also ambiguity about how these attributes contributed to relational dynamics. The theoretical underpinning to the constructs was eclectic, reflecting the influence of psychodynamic, critical and systems approaches but not coalescing around one dominant perspective. One interpretation of the findings would be to posit an ideal-type relationship closely aligned with humanistic, person-centred approaches to social work. Another interpretation would be that the dilemmas of practice are not so easily resolved; indeed, it is in their relationships with service users that social workers are most commonly obliged to confront the familiar paradoxes of their profession. 


\section{References}

Bourdieu, P. (1991) 'The Abdication of the State', in Bourdieu et al. The Weight of the World: Social Suffering in Contemporary Society. Stanford: Stanford University Press, pp. 181-254

Brandell, J. (2013) Psychodynamic social work, New York, Columbia University Press.

Egan, G. (2013) The skilled helper: A problem-management and opportunity-development approach to helping, Brooks/Cole, Belmont: CA.

Fook, J. and Askeland, G. (2006) 'The 'critical' in critical reflection', in White, S., Fook, J. and Gardner, F. (eds), Critical reflection in health and social care, Maidenhead, Open University Press.

Fransella, F., Bell, R. and Bannister, D. (2004) A manual for repertory grid technique (second edition), Chichester, Wiley.

Society: The Journal of Contemporary Social Services, 92(1), pp. 5-11.

Howe, D. (1998) 'Relationship-based thinking and practice in social work', Journal of Social Work Practice, 12(1), pp. 45-56.

Howe, D. (2014) The compleat social worker, Basingstoke, Palgrave Macmillan.

care teams', Health \& Social Care in the Community, 21(1), pp. 47-58.

Joseph, G. and Strain, P. (2004) 'Building positive relationships with young children', Young Exceptional Children, 7(4), pp. 21-28.

Murphy, D., Duggan, M. and Joseph, S. (2013) 'Relationship-based social work and its compatibility with the person-centred approach: Principled versus instrumental perspectives', British Journal of Social Work, 43(4), pp. 703-719.

Neukrug, E., Bayne, H., Dean-Nganga, L. and Pusateri, C. (2013) 'Creative and novel approaches to empathy: A neo-Rogerian perspective', Journal of Mental Health Counseling, 35(1), p. 29.

Nybell, L. (2001) 'Meltdowns and containments. Constructions of children at risk as complex systems', Childhood, 8(2), pp. 213-230.

Ruch, G., Turney, D. and Ward, A. (eds) (2010) Relationship-based social work: Getting to the heart of practice, London, Jessica Kingsley.

Smith, W.K. and Lewis, M.W. (2011) 'Toward a theory of paradox: A dynamic equilibrium model of organizing', Academy of Management Review, 36(2), pp. 381-403.

Trevithick, P. (2003) 'Effective relationship-based practice: a theoretical exploration', Journal of Social Work Practice, 17(2), pp. 163-176. 